\title{
VIDEO ALAT BANTU CEK PROSES PRODUKSI DI PT. RODA PRIMA LANCAR
}

\author{
Elsa Lasaufa ${ }^{1}$ \\ Muhamad fariz firmansyah ${ }^{2}$ \\ Refi setiawan dandi ${ }^{3}$ \\ ${ }^{I}$ Dosen STMIK Raharja \\ ${ }^{2,3}$ Mahasiswa STMIK Raharja \\ Jl. Jendral Sudirman No. 40, Modernland, Tangerang \\ Email : elsa.lasaufa@raharja.info,fariz@raharja.ingfo, refi@raharja.info
}

\begin{abstract}
ABSTRAK
Perkembangan teknologi komputer khususnya bidang multimedia, audio visual dan broadcasting sudah sangat berkembang pesat saat ini serta semakin luasnya kebutuhan akan informasi pada masyarakat, maka semakin banyak kontribusi baru dalam menyajikan company profile baik sebagai media informasi maupun sebagai media promosi. PT. Roda Prima Lancar. bergerak di bidang Metal Manifacturing yang memproduksi beragam produk, produksi terbesarnya adalah produk untuk otomotif roda dua khususnya serta memiliki pelanggan-pelanggan yang tersebar di dalam pulau jawa dan luar pulau dan menjadi salah satu perusahaan besar di indonesia. Dengan tujuan untuk memperkenalkan identitas dan keseluruhan informasi yang terkait didalamnya. Permasalahan yang bisa diangkat menjadi topik observasi laporan skripsi kali ini adalah PT. Roda Prima Lancar, tentunya menginginkan penyajian informasi yang efektif, akurat dan menarik dari segi tampilan maupun isi konten didalamnya. Agar menghasilkan rancangan media berbasis video yang baik dan berkualitas digunakan aplikasi penunjang adobe photoshop, After Effek, Sony Vegas Pro, Adobe Premier, Penyajian informasi yang dikemas dalam bentuk video company profile dirasa sangat berguna untuk tujuan tersebut. Diharapkan video company profile ini bermanfaat dan bisa diimplementasikan oleh PT. Roda Prima Lancar.
\end{abstract}

Kata kunci : Video, teknologi, multimedia, informasi, promosi.

\begin{abstract}
The development of computer technology especially in the field of multimedia, audiovisual and broadcasting already is growing rapidly today as well as of the vast need for information on the community, the more fresh contribution to the company profile serves as both a medium of information as well as a media campaign. PT. Current Prima wheels. Metal Manifacturing engaged in the manufacture of products, with the largest production of products for automotive wheels are two in particular and has customers spread across the island of Java and the outer islands and became one of the big companies in Indonesia. With the aim to introduce overall identity and related information therein. Problems that can be lifted into the topic of thesis report this observation is PT. Current Prima wheels, of course, want the effective presentation of information, accurate and attractive in terms of appearance and the content therein. Presentation of information required in the form of a video company profile is considered very useful for the purpose. Expected video company profile is beneficial and can be implemented by PT. Current Prima wheels.
\end{abstract}

Keywords: Video, technology, multimedia, information, promotion.

Vol.3 No.1 - Februari 2017 


\section{PENDAHULUAN}

Bentuk aplikasi multimedia yang digunakan adalah media komunikasi audio visual, yang merupakan sebuah sarana promosi ataupun sosialisasi yang efektif dalam penyampaian kepada calon customer. Oleh karena itu pengguna media komunikasi audio visual sangat dibutuhkan dalam pengenalan diri sebuah perusahaan atau lembaga. Pemberian informasi merupakan suatu usaha yang dibutuhkan perusahaan karena dengan adanya informasi perusahaan, maka perusahaan akan mendapatkan keuntungan yaitu dikenal secara luas.

PT. Roda Prima Lancar dituntut untuk memenuhi standar kualitas hasil produksi yang sangat baik secara fungsi juga secara estetika. Oleh karena setiap individu maupun kelompok di dalam perusahaan tersebut harus mengetahui segala hal yang berkaitan dengan penunjang hasil produksi, karyawan sebagai aset perusahaan harus juga dibekali dengan informasi dan pengetahuan yang sesuai dengan bidang kerja yang dijalaninya, karena bila seorang karyawan tidak mengetahui dengan pasti apa yang dikerjakan maka dapat dipastikan pekerjaan yang dihasilkan tidak dapat optimal bahkan dapat merugikan perusahaan. Berdasarkan hal tersebut penulis dapat mengambil kesimpulan adalah perlu adanya media informasi dan pengetahuan yang disampaikan kepada karyawan yang membidangi suatu jenis pekerjaan dengan cara penyampaian informasi dan pengetahuan melalu media video, penulis mengambil salah satu jenis pekerjaannya yaitu mendesain alat bantu cek dan dijadikan tema menjadi Video Perancangan Alat Bantu Cek Proses Produksi Di PT. Roda Prima Lancar.

\section{RUMUSAN MASALAH}

PT Roda Prima Lancar merupakan perusahaan yang bergerak dibidang Metal Manifacturing yang memproduksi beragam produk, produksi terbesarnya adalah produk untuk otomotif roda dua khususnya serta memiliki pelanggan-pelanggan yang tersebar di dalam pulau jawa dan luar pulau. Karena produk yang dihasilkan adalah untuk komponen kendaraan bermotor roda dua, Permasalahan yang melatar belakangi penelitian ini adalah kurangnya media video yang digunakan oleh PT. Roda Prima Lancar dalam mempromosikan secara keseluruhan apa yang ada dan disediakan oleh PT. Roda Prima Lancar, karena dalam melaksanakan suatu promosi masih menggunakan sebuah media promosi berupa media cetak, maka dari itu dibuatlah suatu teknik promosi baru untuk PT. Roda Prima Lancar dengan menggunakan Media Video.

\section{LANDASAN TEORI}

\section{Konsep Dasar Video}

video adalah adalah teknologi untuk menangkap, merekam, memproses, mentransmisikan dan menata ulang gambar bergerak. Biasanya menggunakan film seluloid, sinyal elektronik, atau media digita ${ }^{3}$.

\section{Definisi Audio Visual}

Audio visual merupakan gabungan dari dua kata yaitu audio yang berarti suara dan visual yang berarti gambar, atau dengan kata lain menjelaskan, "Audio Visual adalah alat peraga yang dapat dilihat dan didengar dalam hal ini gambar yang bergerak menimbulkan suara ${ }^{1}$."

Vol.3 No.1 - Februari 2017 


\section{Definisi Broadcasting}

Broadcasting adalah distribusi audio visual atau video yang mengirimkan sinyal program untuk penonton. Para penonton mungkin masyarakat umum yang relatif besar subpenonton, seperti anak-anak atau orang dewasa muda ${ }^{5}$.

\section{Konsep Dasar Informasi}

Informasi adalah data yang diolah menjadi bentuk yang lebih berguna dan lebih berarti bagi yang menerimannya, informasi disebut juga data yang diproses atau data yang memiliki $\operatorname{arti}^{7}$.

\section{Nilai Informasi}

Nilai informasi (value of information) ditentukan oleh dua hal, yaitu manfaat dan biaya untuk mendapatkannya. Suatu informasi dianggap bernilai kalau manfaatnya lebih efektif dibandingkan dengan biaya untuk mendapatkannya. Pada kenyataanya, nilai informasi tidak mudah untuk dinyatakan dengan ukuran yang bersifat kuantitatif ${ }^{2}$.

\section{Pengertian Promosi}

Promosi adalah suatu bentuk komunikasi pemasaran. Yang dimaksud dengan komunikasi pemasaran adalah aktivitas pemasaran yang berusaha menyebarkan informasi, mempengaruhi atau membujuk dan mengingatkan pasar sasaran atas perusahaan dan produknya agar bersedia menerima dan loyal pada produk yang ditawarkan perusahaan yang bersangkutan ${ }^{4}$.

\section{Program Aplikasi Penunjang Video Sony Vegas Pro}

Sony Vegas Pro adalah sebuah software khusus untuk video dan audio editing. Saat ini Sony Vegas Pro bukan menjadi tandingan Adobe premire, sementara Sony Vegas Pro memang belum sepopuler Adobe premire yang didukung begitu banyak plug-in. Selain itu, Sony Vegas Movie studio juga merupakan program video editing yang powerful dan membuat DVD yang berkualitas yang mana selalu diberikan oleh Sony untuk banyak produk $^{9}$.

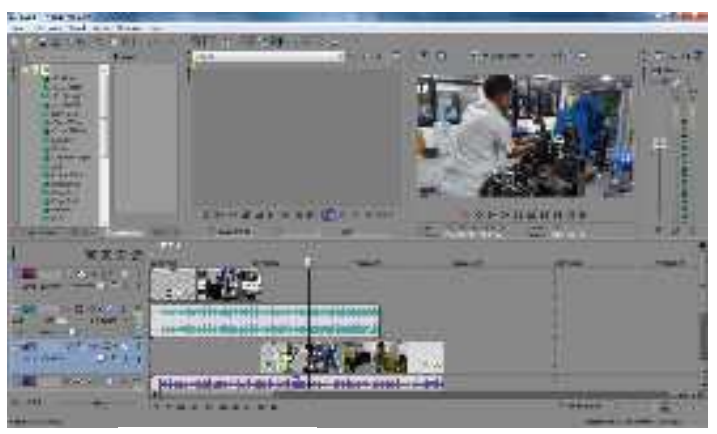

\section{Gambar 1 Sony Vegas Pro}

\section{Adobe Premiere Pro}

Dimasa lalu pengeditan dan memanipulasi video untuk membuat sebuah film, membutuhkan berbagai macam peralatan video editing yang harganya relatif sangat mahal, tapi saat ini dengan komputer multimedia dan program aplikasi video editing seperti Vol.3 No.1 - Februari 2017 
Pinnacle Studio, Ulead Video atau Adobe Premiere pengeditan dan memanipulasi sebuah video dapat dilakukan dengan mudah, cepat dan murah ${ }^{8}$.

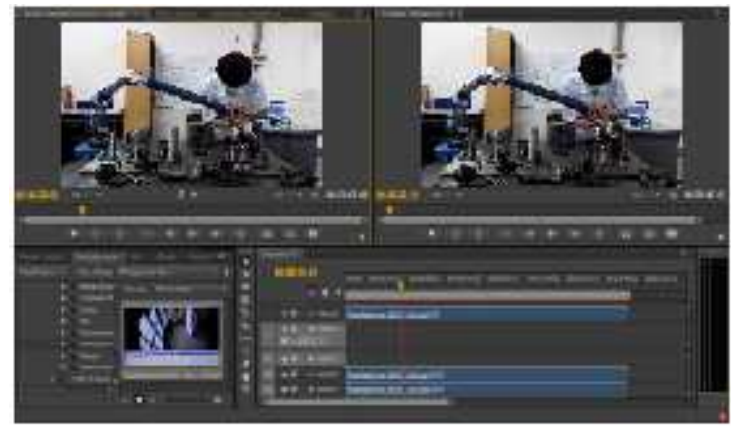

Gambar 2. Adobe Premiere Pro

\section{Adobe After Effect}

Adobe after effect merupakan software motion graphics yang dapat digunakan sebagai software compositing, animasi dan video effect ${ }^{6}$.

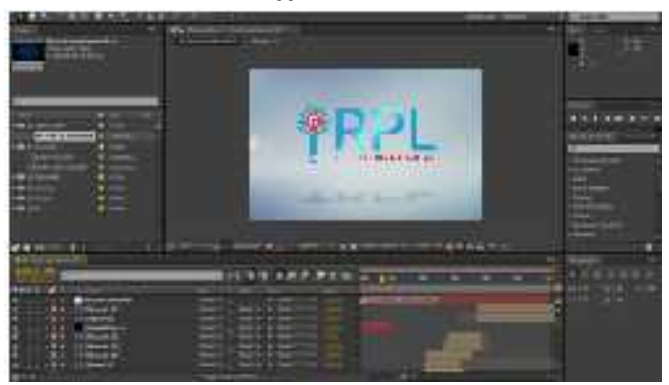

Gambar 3. Adobe After Effect

\section{Adobe Photoshop}

Adobe Photoshop adalah suatu program aplikasi yang bisa menunjang bagi para pemakai untuk mewujudkan bentuk desain dengan membuat dan manipulasi gambar dan juga menyimpan banyak rahasia dan $\operatorname{trik}^{10}$.

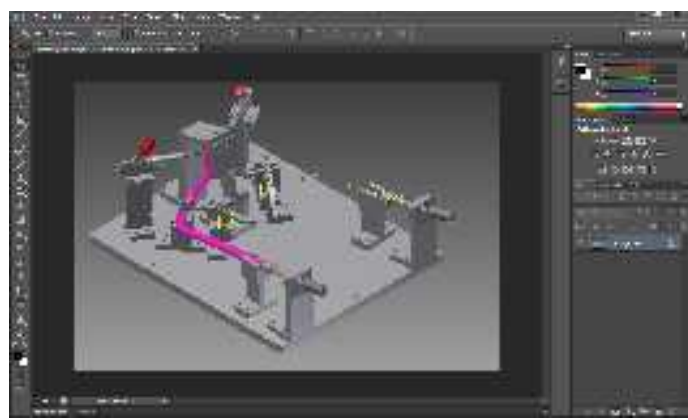

Gambar 4. Adobe Photoshop

\section{PROGRAM APLIKASI PENUNJANG}

\section{Literature Review}

1 Pembuatan Video Company Profile Berbasis Multimedia Pada Sekolah Menengah Pertama Negeri 4 Karanganyar adalah salah satu Jurnal yang dibuat oleh Sesar Wahyu E.P sebagai mahasiwa Nasional Informatika dan Komputer FTI UNSA Surakarta. Vol.3 No.1 - Februari 2017 
Penelitian ini menjelaskan tentang kurangnya media publikasi berbentuk audio visual yang berbentuk video profil. Maka dari itu saya membuat video profile berbasis multimedia untuk sekolah menengah pertama negeri 4 karanganyar.

2. Pembuatan Perancangan Company Profile Berbasis Video Sebagai Media Promosi Smk Muhammadiyah 1 Kepanjen Malang. Skripsi ini di buat oleh Fariz Setia Kusuma penelitian ini menjelelaskan tentang kurangnya sarana atau media publikasi yang dimiliki oleh SMK Muhammadiyah 1 Kepanjen, dan hasil video tersebut akan digunakan oleh Muhammadiyah 1 Kepanjen.

3. Pembuatan Perancangan Video Profile Potensi Wisata Kabupaten Pati, jurnal ini di buat oleh Surya Parulian Halim, Deny Tri Ardianto, Erandaru Srisanto, selaku mahsiswa Universitas Kristen Petra. Penelitian ini menjelaskan tentang kurangnya sarana atau media publikasi yang dimiliki oleh Wisata Kabupaten Pati, dan tujuan dari penelitian ini adalah untuk menghasilkan video profile yang akan digunakan oleh Wisata Kabupaten Pati.

4. Penerapan Teknologi Multimedia Dalam Pembuatan Company Profile Dan Sarana Promosi SLTPN 2 Prambanan, Klaten adalah salah satu judul tugas akhir yang di buat oleh Muhammad Firdaus, Agung Setya Nugraha, Anjang Bawono, Tiar Pratomo selaku mahasiwa STMIK AMIKOM Yogyakarta. Penelitian ini menjelasan tentang Pembuatan Company Profile Dan Sarana Promosi SLTPN 2 Klaten.

5. Pengembangan media video pembelajaran sains bermuatan nilai ketuhanan dan kecintaan terhadap lingkungan, Lampung adalah salah satu judul Skripsi yang dibuat oleh Didi Rahmadi selaku mahasiswa Universitas Lampung. Penelitian ini menjelaskan tentang pembelajaran sains yang mengalami kesulitan dalam mempublikasikan kecintaan terhadap lingkungan, maka dibuatlah solusi yaitu sebuah media video pembelajaran sains bermuatan nilai ketuhanan dan kecintaan terhadap lingkungan.

6. Pengaruh Multimedia Pinnacle Studio Terhadap Hasil Belajar Peserta Didik Pada Pembelajaran Ekonomi Di SMA Negeri 10 Palembang, Palembang adalah salah satu judul Skripsi yang dibuat oleh Revo Ade Cahyo, Prof. Dr. H. M. Djahir Basir, Deskoni selaku mahasiswa Universitas Palembang. Penelitian ini menjelaskan tentang pembelajaran ekonomi SMAN 10 palembang mengalami kesulitan dalam memplubikasikan Multimedia Pinnacle Studio Terhadap Hasil Belajar Peserta Didik Pada Pembelajaran Ekonomi Di SMA Negeri 10 Palembang.

\section{METODE PENELITIAN}

Agar perolehan data lebih akurat dipenelitian ini, terdapat beberapa penerapan metode, yaitu : (1). Metode Analisa Permasalahan. Metode ini merupakan suatu metode yang digunakan untuk menentukan topik permasalahan penelitian, dalam hal ini dilakukan dengan bentuk interview yang menanyakan tentang permasalahan - permasalahan yang terdapat pada lembaga instansi yang terkait dengan proses mempromosikan perusahaan (2). Metode Pengumpulan Data yaitu cara untuk mendapatkan data dengan jalan pengamatan secara langsung ke lokasi (Observasi), Interview ataupun dari kajian pustaka; (3).Analisa Data berupa pengolahan data atau informasi yang diangkat dari hasil 
perancangan dan penelitian terhadap video PT. Roda Prima Lancar yang akan dianalisa dan diolah menggunakan software atau aplikasi program yang mendukung dalam proses perancangan. (4). Metode Analisa Perancangan, dalam produksi Perancangan video Sebagai Media Promosi dan informasi pada PT. Roda Prima Lancar dipergunakan aplikasi - aplikasi penunjang diantaranya aplikasi Sony Vegas Pro, Adobe Premiere Pro, Adobe After Effect dan Adobe Photoshop, untuk pembuatan bumper dari video, Sony Vegas Pro sebagai pengolah logo untuk ditampilkan di video, Adobe Photoshop dipergunakan untuk hasil akhir dari penggabungan desain yang sudah diambil (5). Konsep Dasar Media berisi mengenai Preproduction, Production, dan Postproduction.

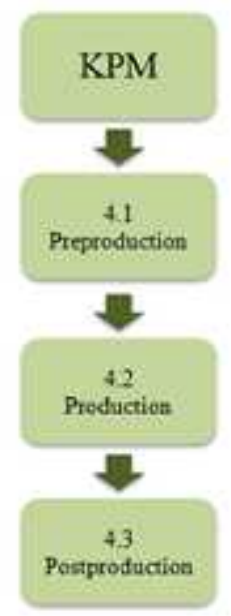

\section{Gambar 5. KPM}

\section{Preproduction}

Untuk Preproduction adalah langkah dimulainya ide, perencanaan dan persiapan dari konsep produksi media. Ada 7 (tujuh) langkah preproduction dalam konsep produksi media, dimulai dari ide yang dituangkan secara sistematis, lalu diikuti dengan pembuatan sinopsis, script writting dan storyboard, 2 (dua) tahapan terakhir adalah pemilihan pemain dan crew dan setting alat. Semua tahapan yang ada harus sesuai time schedule yang ditetapkan.

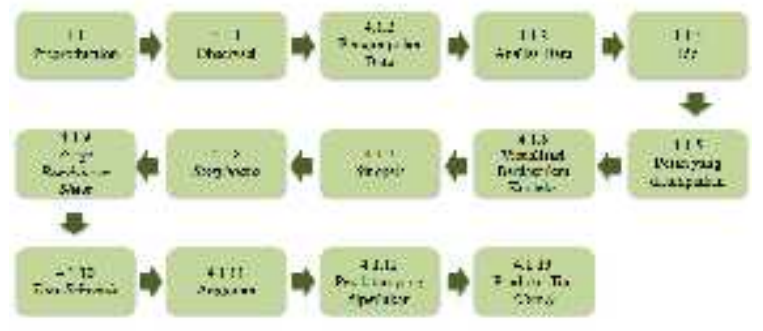

\section{Gambar 6. Preproduction}

\section{Storyboard}

Storyboard adalah rancangan berupa gambar yang dilengkapi dengan petunjuk atau catatan pengambilan gambar untuk kebutuhan shooting. Selama proses pra produksi, perencanaan Vol.3 No.1 - Februari 2017 
yang berhubungan dengan visualiasasi yang akan dibuat membutuhkan storyboard sebagai media bantuannya.

\section{Scene 1}

Bola Dunia Dan Peta Indonesia

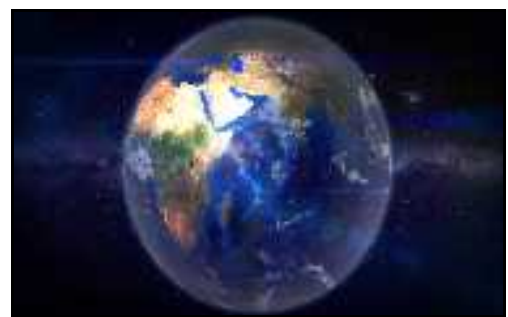

Gambar 7. Bola Dunia dan Peta Indonesia

Scene 2

Ext/Time Lapse Kawasan Industri (Full Shoot)

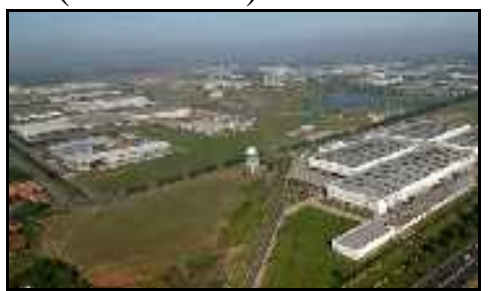

Gambar 8. Time Lapse Kawasan Industri

Scene 3

Logo Pt. Roda Prima Lancar

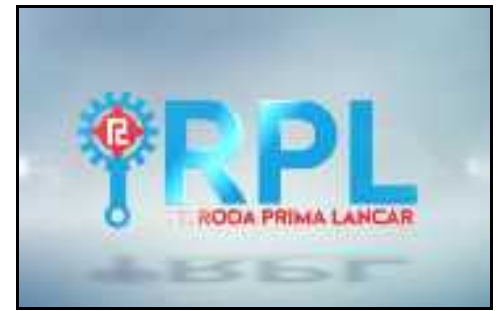

Gambar 9. Logo PT. Roda Prima Lancar

\section{Scene 4}

Ext/Gedung Pt. Roda Prima Lancar/Pagi (Full Shoot)

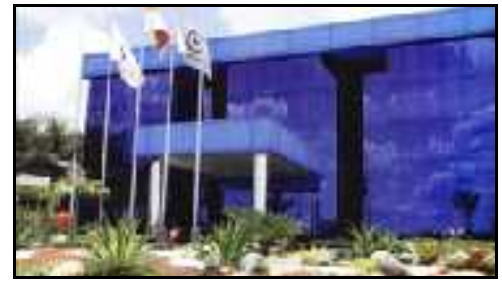

Gambar 10. Gedung PT. Roda Prima Lancar

Vol.3 No.1 - Februari 2017 


\section{Scene 5}

Int/Produk - Produk Yang Dihasilkan (Full Shot)

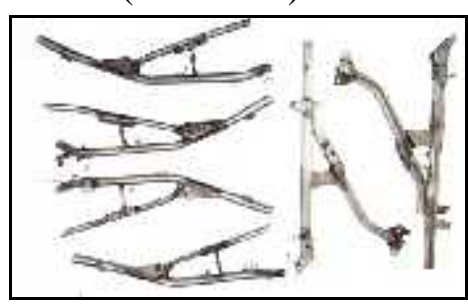

Gambar 11. Produk-produk yang dihasilkan

\section{Scene 6}

Int/Kegiatan Briefing Pagi (Medium Shoot)

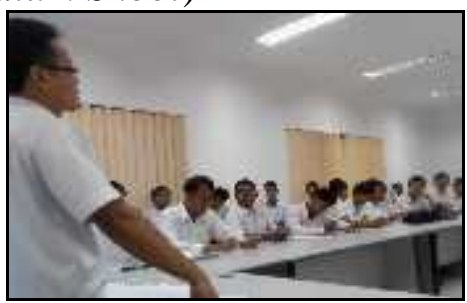

Gambar 12. Kegiatan Briefing Pagi

\section{Scene 7}

Ext/Kegiatan Produksi/Welding (Medium Shoot)

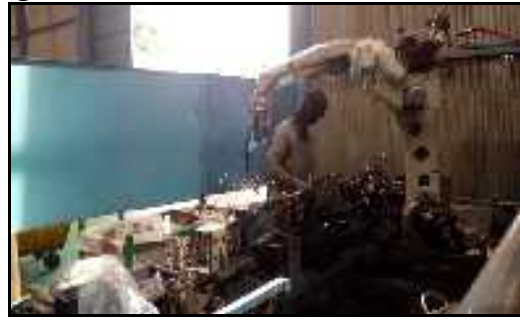

Gambar 13. Kegiatan Produksi/Welding

Scene 8

Ext/ Kegiatan Produksi/Press (Medium Shoot)

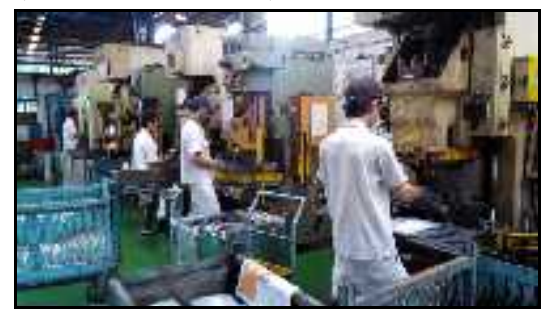

Gambar 14. Kegiatan Produksi/Press

Vol.3 No.1 - Februari 2017 
Scene 9

Ext/ Kegiatan Operasional Alat Bantu Cek (Medium

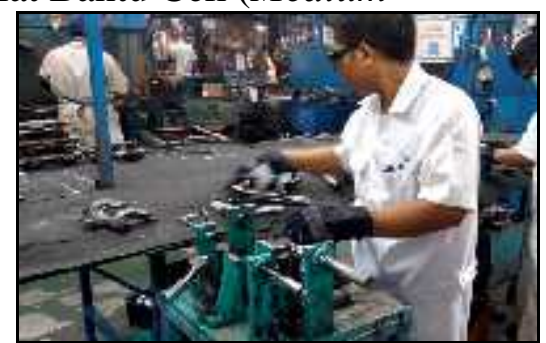

Gambar 15. Kegiatan Operasional Alat Bantu Cek

Scene 10

Tulisan Judul Video

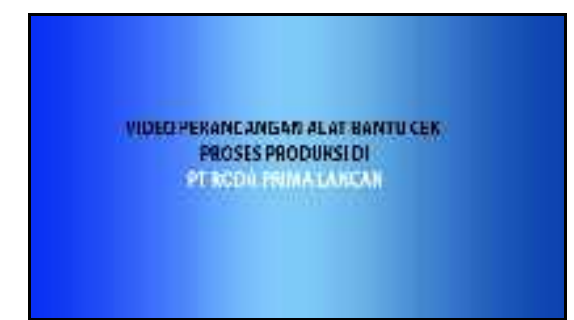

Gambar 16. Tulisan Judul Video

Scene 11

Penjelasan Komponen Alat Bantu Cek

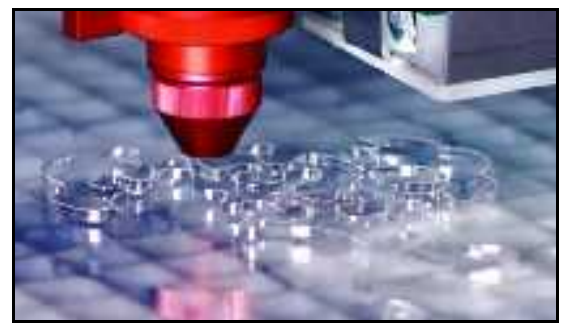

Gambar 17. Penjelasan Komponen Alat Bantu Cek

Scene 12

Ext/ Kegiatan Operasional Alat Bantu Cek (Medium Shoot)

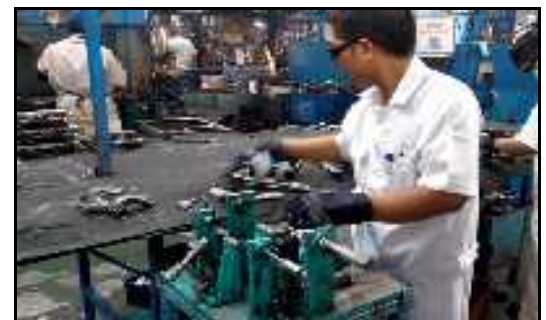

Gambar 18. Kegiatan Operasional Alat Bantu Cek

Vol.3 No.1 - Februari 2017 


\section{Scene 13}

Int/ Kegiatan Trial Alat Bantu Cek (Medium Shoot)

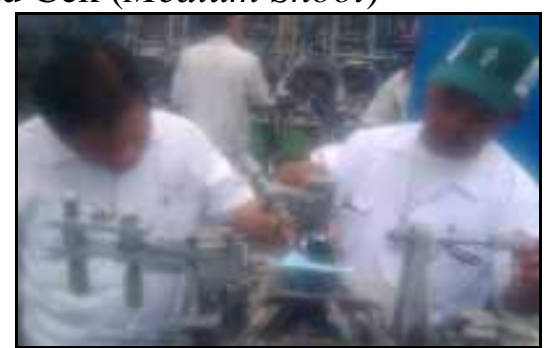

Gambar 19. Kegiatan Trial Alat Bantu Cek

\section{Scene 14}

Int/ Kegiatan Pengukuran Alat Bantu Cek (Medium Shoot)

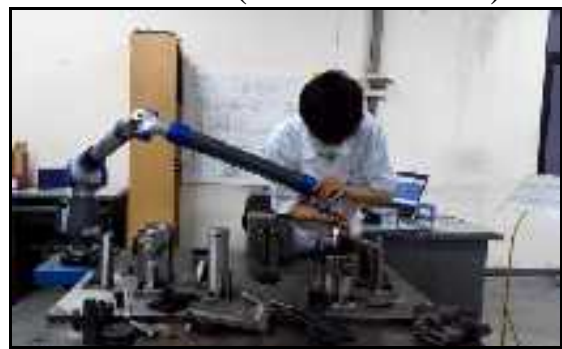

Gambar 20. Kegiatan Pengukuran Alat Bantu Cek

Scene 15

Int/ Kegiatan Setting Alat Bantu Cek (Medium Shoot)

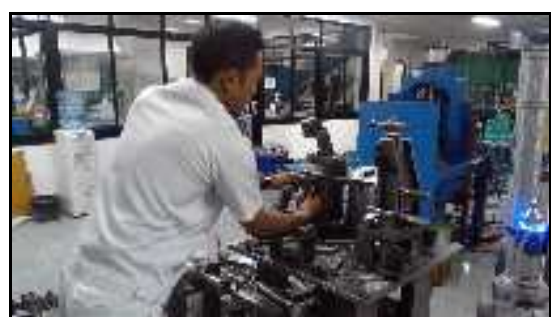

Gambar 21. Kegiatan Setting Alat Bantu Cek

Scene 16

Ext/ Kegiatan Proses Workshop Alat Bantu Cek (Medium Shoot)

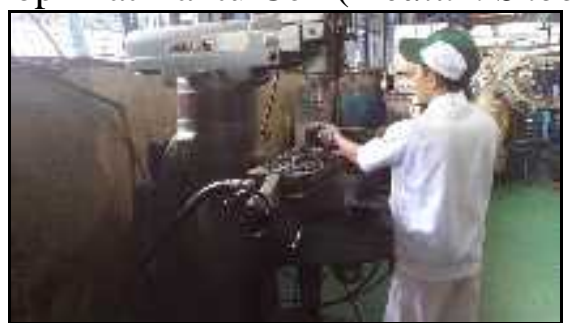

Gambar 22. Kegiatan Proses Workshop Alat Bantu Cek 


\section{Scene 17}

Int/ Kegiatan Proses Perancangan Alat Bantu Cek

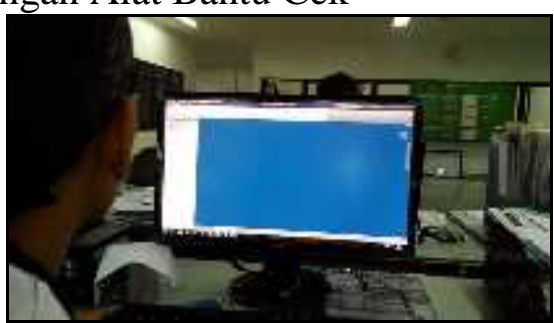

Gambar 23. Kegiatan Proses Perancangan Alat Bantu Cek

\section{Scene 18}

Ext/Gedung Pt. Roda Prima Lancar/Sore (Full Shoot)

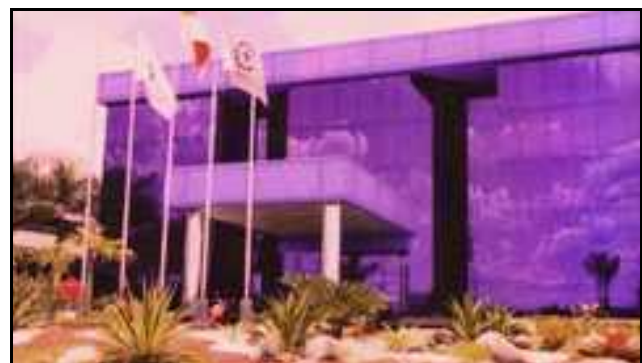

Gambar 24. Gedung PT Roda Prima Lancar

Scene 19

Ext/Kegiatan Karyawan Pulang Kerja/Sore (Full Shoot)

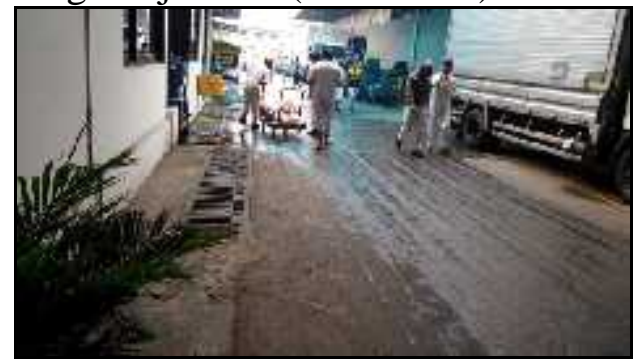

Gambar 25. Kegiatan Karyawan Pulang Kerja

Scene 20

Logo Pt. Roda Prima Lancar

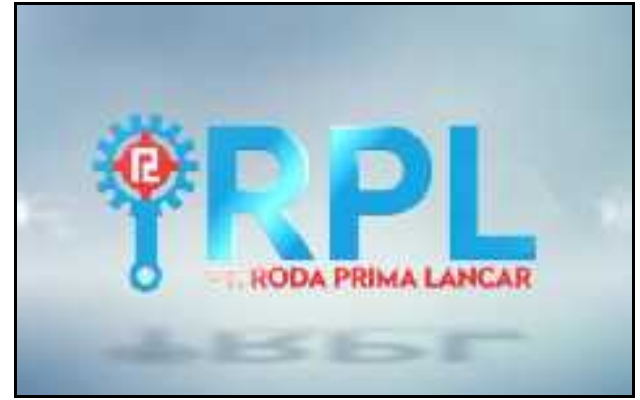

Gambar 26. Logo PT. Roda Prima Lancar

Vol.3 No.1 - Februari 2017 


\section{Setting Alat}

Dalam pembuatan video profile menggunakan alat Camera, Monopod, dan Microphone. Untuk Camera yang digunakan penulis menggunakan Camera Digital. Dalam Video audio visual ini banyak digunakan dilokasi dalam lingkungan perusahaan. Sedangkan pengambilan suara menggunakan Mic Pro Kenwood KW-321

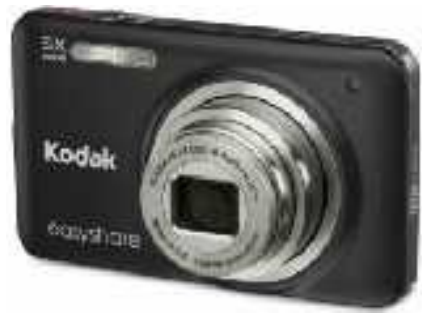

\section{Gambar 27. Camera Digital}

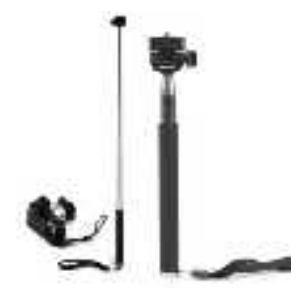

Gambar 28. Monopod

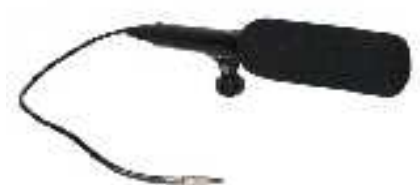

Gambar 29 Mic Pro Kenwood KW-321

\section{Production}

Production adalah bekerjasamanya pemain dan crew untuk pewujudan dari naskah, storyboard dan tepatnya time schedule yang telah dibuat. Di tahap ini pengambilan gambar (shooting) dibuat. Dari pengambilan gambar di lokasi yang sesuai hingga selesainya Take Script sesuai Time schedule.

\section{Strategi Multimedia}

1. Geografi : Indonesia dan Tempat dimana berlangsungnya OPP (Open Plan Presentation).

2. Demografi :

a. Jenis Kelamin : Pria \& Wanita

b. Kelas Ekonomi : Menengah

c. Sasaran : Calon Customer, Karyawan baru

3. Psikografi:

Relasi dan Karyawan yang ingin lebih mengetahui informasi mengenai video PT Roda

Prima Lancar. 


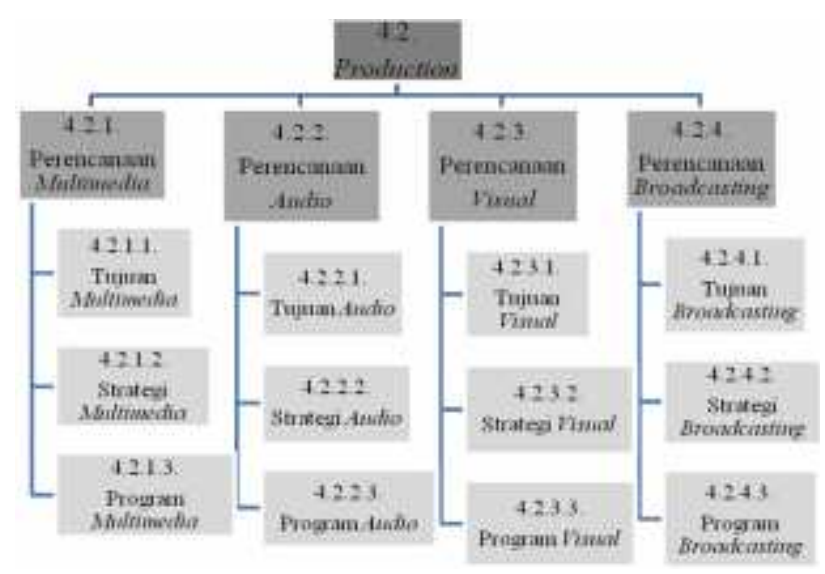

Gambar 30. Production

\section{Postproduction}

Sesuai dengan program broadcasting yang direncanakan bahwa rancangan media ini nantinya akan ditayangkan melalui pemutaran secara langsung pada kegiatan-kegiatan perekrutan maupun event lainnya sesuai kebutihan perusahaan, pada tahapan ini adalah menentukan format yang dibutuhkan, yakni format yang digunakan adalah Format AVI atau MPEG4 agar lebih mudah disaat proses produksi dan pemutarannya.

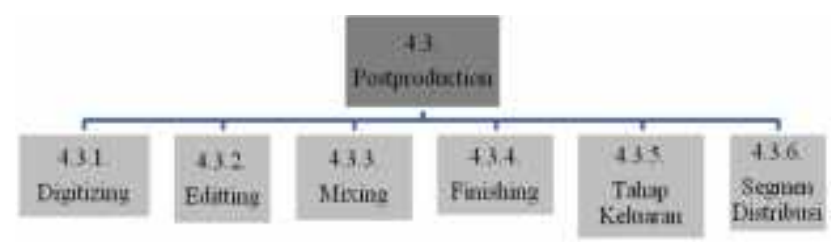

\section{Gambar 31. Postproduction}

\section{KESIMPULAN}

Media video yang dirancang telah memenuhi unsur efektif dan efisien dan telah memberikan promosi dan informasi mengenai produksi, hingga keunggulan dari perusahaan yang dihasilkan serta promosi dan informasi lainnya yang terkait dengan PT Roda Prima Lancar secara detail dan lengkap yang disampaikan. Telah terpenuhinya komponen penunjang promosi yang menarik dan dapat memenuhi kebutuhan masyarakat yaitu dengan membuat sebuah media yang berisikan infomasi-informasi mengenai PT Roda Prima Lancar tersebut, yang dikemas kedalam bentuk video dengan perancangan konsep yang menarik, dimana terdapat: cara kerja mesin produksi.

Target yang ingin dicapai oleh PT Roda Prima Lancar setelah diimplementasikannya media video ini diharapkan bisa meningkatkan penjualan dari PT Roda Prima Lancar menjadi lebih meningkat, dengan bertambahnya customer menjadi lebih meningkat dari target sebelumnya. 


\section{Daftar Pustaka}

[1] Arifin, Eva. 2012. Broadcasting To Be Broadcaster. Yogyakarta: Graha Ilmu.

[2] Atmohoetomo. 2011. Media Audio Visual Pendidikan dan Proses Produksi Programnya. Yogyakarta: Pusdiklat Perpustakaan IKIP.

[3] Ayuningtyas, Melvy. 2011. "Ngedit Video Dengan Adobe Premiere CS3", Dunia Komputer. Yogyakarta.

[4] Binanto, Iwan. 2013. Multimedia Digital (Dasar Teori dan Pengembangannya). Yogyakarta: Andi.

[5] Halim, Cipta. 2010. “Tips Praktis Promosi Online Untuk Berbagai Event”. Gramedia. Jakarta.

[6] Lovure Cyber Team. 2012. Smart Book Video Editing. Jakarta: Kunci Kom.

[7] Lusyani Sunarya, Maimunah, dan, Nina Larasati. 2012. Media Company Profile Sebagai Sarana Penunjang Informasi dan Promosi. Tangerang: Perguruan Tinggi Raharja. (Journal CCIT Vol.5 No.3 - Mei 2012).

[8] Rahardja, Untung, Sugeng Widada, dan Dewi Imaniar Destrianti. 2010. KPM Sebagai Pedoman Produksi Media MAVIB (Multimedia Audio Visual and Broadcasting). Tangerang: Perguruan Tinggi Raharja. (Journal CCIT Vol.3 No.2 - Januari 2010).

[9] Waloeya, Yohan Jari. 2012. Seri Belajar Kilat Adobe After Effect CS5. Yogyakarta: Andi.

[10] Wibowo, Ibnu Teguh. 2013. Belajar Desain Grafis. Jakarta: Grasindo. 